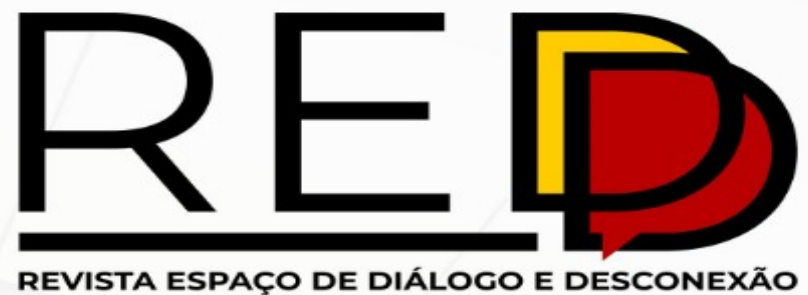

Link: https://periodicos.fclar.unesp.br/redd/index

\title{
Habitus e subjetivação a partir de P. Bourdieu e M. Foucault: Contribição do núcleo de es- TUDOS E PESQUISA SOBRE SOCIEDADE, EMOÇõES, PODER, ORGANIZAÇÃO E MERCADO (NESPOM)
}

\author{
Maria Chaves Jardim ${ }^{1 *}$; Gabriel Papa Ribeiro Esteves ${ }^{2 *}$ \\ ID ORCID: ${ }^{1}$ http://orcid.org/0000-0001-5715-1430; ${ }^{2}$ https://orcid.org/0000-0002-4792-4273 \\ Autor para correspondência e-mail: nespom.oficial@gmail.com
}

\section{Palavras-chave}

Habitus

Subjetivação

Agente

Sujeito

NESPOM-FCLAr

Keywords

Habitus

Subjectivation

Agent

Subject

NESPOM-FCLAr

Palabras clave

Subjetivación

Agente

Sujeto

NESPOM-FCLAr

\section{RESUMO}

Com inspiração em Michel Foucault e Pierre Bourdieu, o artigo considera o indivíduo e sua subjetividade como o resultado de forças sociais em equação com práticas discursivas (FOUCAULT, 1985) e com seu habitus (BOURDIEU, 1979). Contudo, apesar dos inegáveis constrangimentos sociais e das relações de poder nas quais os indivíduos estão inseridos, assumimos como hipótese que estes possuem algum tipo de escape para expressar a sua criatividade, para além da mera reprodução da ordem social. Isso seria possível porque cada indivíduo seria detentor de uma biografia, que conteria uma gramática de interpretação do mundo, um habitus, nas palavras de Pierre Bourdieu e uma subjetivação ou "cuidado de si", conforme Foucault (1985). Esse argumento tem inspiração em Bourdieu e em Foucault e exemplificamos com quatro pesquisas empíricas desenvolvidas no NESPOM Faculty of Sciences and Letters of Araraquara - UNESP / FCLAr.

\begin{abstract}
Habitus And subjectivation from P. Bourdieu And M. Foucault: Contribution OF THE CORE OF STUDIES AND RESEARCH ON SOCIETY, EMOTIONS, POWER, ORGANIZATION AND MARKET (NESPOM)

With inspiration in Michel Foucault and Pierre Bourdieu, the article considers the individual and his subjectivity as the result of social forces in equation with discursive practices (FOUCAULT, 1985) and with his habitus (BOURDIEU, 1979). However, despite the undeniable social constraints and power relations in which individuals are inserted, we hypothesize that they have some kind of escape to express their creativity, beyond the mere reproduction of social order. This would be possible because each individual would be the holder of a biography, which would contain a grammar of interpretation of the world, a habitus, in the words of Pierre Bourdieu and a subjectivation or "self-care", according to Foucault (1985). This argument is inspired by Bourdieu and Foucault and exemplified by four empirical researches developed in NESPOM-FCLAr.
\end{abstract}

\section{RESUMEN \\ Habitus Y Subjetivación A Partir De P. Bourdieu Y M. Foucault: contribición DEL NÚCLEO DE ESTUDIOS E INVESTIGACIÓN SOBRE SOCIEDAD, EMOCIONES, PODER, OR- GANIZACIÓN Y MERCADO (NESPOM) \\ Con inspiración en Michel Foucault y Pierre Bourdieu, el artículo considera al individuo y su subjetividad como el resultado de fuerzas sociales en ecuación con prácticas discursivas (FOUCAULT, 1985) y con su habitus (BOURDIEU, 1979). Sin embargo, a pesar de las innegables limitaciones sociales y de las relaciones de poder en las que los individuos están insertos, asumimos como hipótesis que éstos poseen algún tipo de escape para expresar su creatividad, además de la mera reproducción del orden social. Esto sería posible porque cada individuo poseía una biografía, que contendría una gramática de interpretación del mundo, un habitus, en las palabras de Pierre Bourdieu y una subjetivación o "cuidado de sí”, según Foucault (1985). Este argumento tiene inspiración en Bourdieu y en Foucault y ejemplificamos con cuatro investigaciones empíricas desarrolladas en el NESPOM- Facultad de Ciencias y Letras de Araraquara - UNESP / FCLAr.}




\section{INTRODUÇÃo}

Um dos principais debates da teoria social contemporânea é o da relação indivíduo, sociedade e subjetividade. Busca-se entender como a prática do indivíduo influencia na dinâmica estrutural, que por sua vez influencia a práxis. Uma das polêmicas é entender o poder de agência de um indivíduo em relação à estrutura com a qual interage, ou, nas palavras de Foucault (1985), como se tornar um sujeito da enunciação e não do enunciado.

Em nossa perspectiva, o indivíduo seria um ser criativo em potencial, posto que possui uma subjetividade, ou seja, um conjunto de características individuais e singulares, que, apesar de construídos socialmente, dão ao indivíduo certa capacidade singular de julgamento, que orienta suas escolhas, sua racionalidade e as tomadas de posições. Ou seja, um indivíduo, com uma biografia construída na socialização, primeiramente na família, em seguida na escola e em demais espaços sociais por onde interage, construindo um habitus-individual e um habitus-coletivo, sendo este último resultado da afinidade entre agentes, formando o habitus de classe (BOURDIEU, 1979).

Com inspiração em Foucault e Bourdieu, esse artigo considera que a subjetividade do indivíduo é resultado de forças sociais em equação com formações discursivas permeadas de poder (FOUCAULT, 1985) em diálogo com seu habitus (BOURDIEU, 1979). Contudo, apesar dos inegáveis constrangimentos sociais e das relações de poder nas quais estão inseridos, assumimos como hipótese que os indivíduos possuiriam algum tipo de escape para expressar a sua criatividade, para além da mera reprodução da ordem social. Isso seria possível porque cada indivíduo seria detentor de uma biografia, que conteria uma gramática de interpretação do mundo, um habitus, nas palavras de Pierre Bourdieu e uma capacidade de subjetivação, na qual expressaria o "cuidado de si” (FOUCAULT, 1985). Exemplificaremos essa ideia a partir de quatro pesquisas desenvolvidas no Núcleo de Estudos e Pesquisa sobre Sociedade, Emocões, Poder, Organização e Mercado (NESPOM) da Faculdade de Ciências e Letras de Araraquara - UNESP/FClAr, as quais têm como inspiração o poder de agência do agente social (BOURDIEU, 1979) e a "subjetivação" (FOUCAULT, 1985).

O artigo está organizado da seguinte forma. Além dessa introdução e da conclusão, possui a seção 1, na qual abordamos o pensamento de Pierre Bourdieu direcionado para os conceitos que nos interessam nesse texto (espaço social e habitus); a seção 2, quando abordamos o pensamento de Michel Foucault, especialmente o tema da subjetivação a partir do "cuidado de si" e finalmente, a seção 3, na qual apresentamos quatro pesquisas desenvolvidas no Nespom-FCLAr, que utilizaram o ferramental teórico de Pierre Bourdieu e de Michel Foucault.

\section{Pierre Bourdieu: habitus, biografia e espaço social}

Segundo Pierre Bourdieu, o mundo social deve ser entendido a partir do conceito de espaço social, definido pelo autor como o lugar de interação social entre agentes, sendo que o lugar ocupado pelo agente no espaço social, seria determinado pelo conjunto de capitais detidos por este (capital econômico, social, cultural), que no seu conjunto formam os trunfos simbólicos detidos no espaço social (BOURDIEU, 1996). Nesse sentido, o espaço das posições sociais se retraduz em um espaço de tomadas de posição, intermediadas pelo espaço das disposições.

O espaço social é construído de tal modo que os agentes ou os grupos são distribuídos em função de sua posição nas distribuições estatísticas de acordo com os dois princípios de diferenciação que, em sociedades mais desenvolvidas, como os Estados Unidos, o Japão ou a França, são, sem dúvida, os mais eficientes - o capital econômico e o capital cultural. Segue-se que os agentes têm tanto mais em comum quanto mais próximos estejam nessas duas dimensões, e tanto menos quanto mais distantes estejam delas. As distâncias espaciais no papel equivalem a distâncias sociais (BOURDIEU, 1996, p. 35).

Assim, a posição ocupada no espaço social é importante para a manutenção ou a transformação de um determinado espaço social, que acontece em um contexto de contínua luta para a significação e ressignificação da "verdade", ou da doxa. Nessas lutas simbólicas, fazer uso da violência simbólica é uma estratégia necessária, ainda que não necessariamente consciente ${ }^{2}$ (BOURDIEU, 1996). Portanto, é no espaço social que se dá a interação social dos agentes a partir da afinidade de habitus, que os aproximam e os afastam, criando uma potencialidade objetiva de unidade (Idem).

Importante na concepção de espaço social é o conceito de campo, definido pelo autor como um espaço

${ }^{2}$ Conceito que denota uma maneira de violência suave e doce, que exige a cumplicidade, sem se saber dominado. Sustenta-se no reconhecimento de imposições fundadas na fabricação contínua de crenças que influenciam os indivíduos a alocarem-se socialmente segundo os discursos dominantes legitimamente reconhecidos. 
de sociabilidade estruturado e permeado de conflitos, onde os agentes sociais possuem um habitus que lhes dão uma capacidade de ação prática, resultado da interiorização da externalidade e externalização subjetiva e singular da internalidade. De outra forma, as regras dos campos são incorporadas pelos agentes (colocadas no corpo e na mente) e são devolvidas em forma de ação prática. Logo, os campos são estruturas estruturadas e estruturantes (BOURDIEU, 2000), já que influenciam e são influenciados pelos agentes que o compõe.

Para Bourdieu (2000), cada campo seria dotado de regras de funcionamento próprias, autônomas e interdependentes em relação aos outros campos que compõem o espaço social e permanecem em constante transformação, posto que os indivíduos estejam interagindo e a interação é o desenvolvimento da mudança. No campo social, os agentes ocupam uma posição orientada pelo volume e pela estrutura do capital eficiente daquele campo e pelo quanto conseguem apropriar-se deste capital, agindo segundo suas posições.

O campo pressupõe a interação entre os agentes, com sua história de vida e seu dispositivo cognitivo, que por sua vez orienta visões de mundo, preferências e gostos. Assim, "[...] as relações sociais são depositadas dentro de corpos individuais, na forma de esquemas mentais de percepção e apreciação (cuja articulação, em camadas, compõe o habitus), através dos quais nós experimentamos internamente e construímos ativamente o mundo vivido" (BOURDIEU, 1980, p. 29).

Desta feita, os habitus são gerados direta ou indiretamente pela relação do agente com os campos, com os grupos de sociabilidade e com outros agentes com os quais se relacionam. Assim, o habitus é produzido na socialização, imprimindo singularidade em cada agente social.

Em Bourdieu, o habitus seria um conhecimento adquirido, isto é, o indivíduo incorpora valores e símbolos do meio em que vive e os reproduz em suas ações e pensamentos enquanto agente social, mas sempre ressignificando a realidade a partir do diálogo entre mundo externo apresentado ao indivíduo e o mundo interno, seu habitus, que ajuda a definir suas formas de classificação e de julgamento do mundo. O habitus é a própria visão de mundo do agente, resultante de sua trajetória de vida.

Nesse sentido, o habitus integra experiências passadas e atua como uma matriz de percepções, de apreciações, de ações, de gosto e de tomadas de decisões. Essa "matriz", ou conjunto de disposições, fornece esquemas necessários para a intervenção dos agentes sociais na vida diária. Conforme trata o autor, essas disposições não são fixas. Ademais, não são nem a personalidade e nem a identidade dos indivíduos: "[...] habitus é um operador, uma matriz de percepção e não uma identidade ou subjetividade fixa” (BOURDIEU, 2002, p. 83). Sendo produto da história, o habitus é um sistema de disposições aberto, permanentemente afrontado a experiências novas e permanentemente afetado por elas. Ele é durável, mas não imutável.

Assim, as tomadas de decisões, os discursos e a criação de instituições são resultantes das ações dos agentes, orientadas por certo senso prático, capaz de direcionar tomadas de decisões desde a esfera privada - relacionamentos de simpatias, e/ou antipatias -, até decisões econômicas e políticas. Para Bourdieu, por ser dotado de um habitus, o agente é, ao mesmo tempo, individual-coletivo e coletivo-individual, seu posicionamento no mundo social é resultante das afinidades de disposição, tanto individual quanto coletivo.

Portanto, para Bourdieu, a devolução das regras, em forma de ações práticas, estaria em sintonia com o habitus do individuo; logo, nisso residiria a criatividade do agente diante da sociedade. Nesse sentido, diferentemente do conceito de hábito, que se refere a algo imutável, habitus, seria uma referência ao conceito aristotélico de hexis, que se contrapõe à filosofia estruturalista da ação, pois diferentemente desta, o agente não está reduzido ao papel de suporte da estrutura.

Por tudo isso, o habitus revigora a teoria sociológica contemporânea, pois permite dinamizar o agente social, dando-lhe capacidades de escolhas, sem ignorar, contudo, o coletivo e os constrangimentos sociais criados por este:

Retomando a velha noção aristotélica de hexis, convertida pela escolástica em habitus, eu desejava reagir contra o estruturalismo e sua estranha filosofia da acção que, implícita na noção levi-straussiana de inconsciente, se exprime com toda clareza entre althusserianos, com seu agente reduzido ao papel de suporte - Trager - da estrutura(...) eu desejava pôr em evidência as capacidades $<<$ criadoras $>>$, activas, inventivas do habitus e do agente (que a palavra hábito não diz), embora chamando a atenção para a ideia de que este poder gerador não é o de um espírito universal, de uma natureza ou de uma razão humana, como em Chomsky - o habitus, a hexis, indica a disposição incorporada, quase postural - , mas sim o de um agente em acção (BOURDIEU, 2000, p. 61). 
Trata-se de um marcador simbólico que pode expressar distinção ou desclassificação (BOURDIEU, 1979). Mostra distinção quando expressa acultura dominante, que por sua vez contribui para a integração real da classe dominante, por meio do habitus, assegurando a comunicação imediata entre todos os seus membros e os distinguindo das demais classes sociais. Expressa desclassificação quando apresenta a cultura dos dominados.

A partir de tudo que foi dito, podemos definir o conceito de habitus como um instrumento conceitual que nos auxilia a pensar a relação e a mediação entre os condicionamentos sociais exteriores e a subjetividade dos agentes sociais, dando ênfase ao agente cognitivo, contudo, considerando que a cognição é historicamente constituída como possibilidades.

A seguir, apresentaremos os conceitos de "prática discursiva" e de "subjetivação" em Michel Foucault (1985).

\section{Michel Foucault: Práticas discursivas, poder e subjetividade}

Para Foucault (1986), o sujeito é o indivíduo assujeitado a uma possibilidade de sujeito, contaminado pelas formações discursivas que estão ao seu redor. Por esta perspectiva, cada indivíduo assume discursos específicos, os quais são esperados dele, dado os poderes que se exercem ao seu redor e que o indivíduo também exerce, inclusive ao assumir um discurso.

Desta feita, os sujeitos são construções produzidas pelo social, sendo o social uma materialização de formações discursivas, as quais são difundidas a partir das instituições que introjetam as regras de controle nos indivíduos. Podemos citar como exemplo, a instituição escola, os asilos, as instituições psiquiátricas, o direito, instituições analisadas com profundidade por Foucault durante sua obra.

Em Foucault, o conceito de sujeito pode ser pensado como algo elaborado, de acordo com os poderes que se dão sobre os indivíduos em interação com outros sujeitos, instituições e grupos. Portanto, os indivíduos se posicionam no discurso porque veem nele uma possibilidade de realização da sua subjetividade, sua identidade. Ao se posicionar em um discurso, o indivíduo torna-se sujeito de determinada ordem de discurso, pautada em funções discursivas específicas, de acordo com interesses de grupos e sujeitos disponíveis no assujeitamento de indivíduos e nas relações de poder e interesse em que estes se inserem. Portanto, para Foucault, o sujeito só existiria na prática do discurso, que por sua vez está enraizado em formações discursivas (FOUCAULT, 1996).

Desta feira, o indivíduo é coagido física e ideologicamente a se tornar sujeito, quando é enquadrado em categorias e atribuições, através da inculcação de práticas e discursos, que acaba por constituir indivíduos concretos em sujeitos.

Nesse sentido, o poder exercido nas relações sociais tem o sujeito como seu mais importante efeito, já que o poder produz sujeito a partir das práticas discursivas. Em Foucault, a materialização do poder pode ser evidenciada de duas formas: nas políticas públicas direcionadas para a população e nas técnicas disciplinares que atingem os corpos (poder disciplinar), tornando-os corpos dóceis. Nesse sentido, as práticas dos sujeitos são enquadradas na dinâmica social, assim, o controle da sociedade pela sociedade materializa-se no controle do sujeito.

Nas palavras de Foucault:

Trata-se de alguma maneira de uma microfísica do poder posta em jogo pelos aparelhos e instituições, mas cujo campo de validade se coloca de algum modo entre esses grandes funcionamentos e os próprios corpos com sua materialidade e suas forças. Ora, o estudo desta microfísica supõe que o poder nela exercido não seja concebido como uma propriedade, mas como uma estratégia, que seus efeitos de dominação não sejam atribuídos a uma "apropriação", mas a disposições, a manobras táticas, a técnicas, a funcionamentos; que se desvende nele antes uma rede de relações sempre tensas, sempre em atividade (FOUCAULT, 1986, p. 28).

Nesse contexto, os chamados processos de subjetivação em Foucault, referem-se ao modo como o próprio homem se compreende como sujeito legítimo de determinado tipo de conhecimento, ou melhor, como o sujeito percebe a si mesmo na relação sujeito-objeto. Os processos de objetivação, por sua vez, dizem respeito ao modo como o sujeito pôde se tornar um objeto para o conhecimento. A objetivação e a subjetivação são, portanto, processos complementares que se relacionam por meio do que Foucault resolveu chamar de jogos de verdade, entendidos como modos pelo quais os discursos podem ou não se tornar verdadeiros, de acordo 
com as circunstâncias em que são ditos e as relações de poder envolvidas. Sem negar as relações de poder e as formações discursivas expostas anteriormente, a ideia de subjetivação que queremos chamar a atenção nesse artigo, está na última parte da obra de Foucault, A História da sexualidade volume III: o Cuidado de Si (1985), na qual o autor trabalhou dois conceitos que nos inspiram para refletir sobre a subjetividade, as técnicas de si e a estética da existência. Nesse livro, após análise da moral grega, o autor sugere a possibilidade que cada indivíduo tem de criar seu estilo próprio, visando à produção de si mesmo, como o artesão da beleza de sua vida, sem negar, contudo, a existência das relações de poder, já denunciadas em sua obra anterior (FOUCAULT, 1986; 1988). Nesse momento da sua obra, Foucault defende que "[...] é necessário promover novas formas de subjetivação, rechaçando o individualismo que nos impõem há séculos” (FOUCAULT, 1994, p. 232). O autor identifica que o cuidado de si, entendido como um retorno a si, representaria a busca de subjetivação, já que "O cuidado de si mesmo foi o modo pelo qual os gregos colocaram a questão da liberdade como ética" (FOUCAULT, 1994, p. 712). Nas palavras do autor, estas técnicas eram procedimentos “[...] prescritos aos indivíduos para fixar sua identidade, mantê-la ou transformá-la em função de determinados fins, isso graças a relações de domínio de si sobre si ou de conhecimento de si por si" (FOUCAULT, 1997, p. 109). Portanto, defendendo a existência de uma possibilidade de relação que cada indivíduo estabelece consigo, Foucault (1985) nega o pressuposto da universalidade dos "regimes de verdades"; ou seja, reconhece que as relações de poder se cristalizam em estados de dominação, mas que estas, para se constituírem como regimes de verdades, passam por uma reflexão interior e singular, resultante do conhecimento e da experiência íntima de cada individuo. Nesse momento de sua obra, Foucault busca colocar o sujeito no centro da reflexão, contudo, um sujeito liberado dos atributos que lhe foram dados pelo saber moderno e pelo poder disciplinar e normalizador. Segundo Foucault (1985), esse indivíduo seria orientado por códigos morais, por uma ética, sendo está ultima considerada por Foucault como uma relação consigo mesmo, uma prática, um ethos, um modo de ser. De acordo com Foucault (1985), essa possibilidade de agir sobre si mesmo traria novas formas de subjetivação, apesar da inegável dominação (objetivação) a que o sujeito estaria submetido.

Conceito central para nos fazer entender o processo de subjetivação em Foucault, é o de Ética, a partir do qual é possível refletir sobre a busca de singularidade e de alteridade na formação da subjetividade, apesar da existência de discursos de verdades que assujeitam os sujeitos.

Para Foucault, na moral grega se respeita o caráter individual da conduta, ou seja, a escolha do modo de vida seria uma questão pessoal e o trabalho sobre a própria vida se apoiaria em uma série de técnicas que não teria caráter normativo, nem pretendia se organizar em forma de código. O elemento sobre o qual descansava a moral antiga era o trabalho sobre si, a ascética elevada à categoria de matriz constitutiva do ethos, que implicava na relação do indivíduo consigo mesmo, na relação com os outros e com a verdade.

Em Foucault (1985), modos de subjetivação são formas de atividade sobre si mesmo, ou seja, práticas de constituição do sujeito. O autor argumenta que na antiguidade greco-romana as técnicas de si, que concretamente são técnicas de cuidado de si, possibilitariam aos indivíduos a realização, por eles mesmos, de determinadas operações em seu corpo, em sua alma, em seus pensamentos e principalmente em suas condutas, operando a subjetividade, que significa um estado de estar e permanecer consigo mesmo.

Portanto, a partir desses conceitos, Foucault nos permite pensar a possibilidade para a afirmação de uma maneira singular de se fazer sujeito, de tomar consciência sobre si, para a criação de modos de existência e estilos de vida (formas de subjetivação) dotados do direito à diferença e à variação, capazes de resistir e escapar dos dispositivos de captura de poder e fixar identidades individuais, transformando a vida em uma obra sempre por se fazer. Essa subjetivação seria foco de resistência aos diversos focos de poder e de dominação.

Assim como na Grécia antiga, para o estabelecimento desta relação consigo seria necessário instituir um trabalho de si sobre si mesmo, ou seja, um treinamento de si, que se realizaria através de uma prática, ou seja, era necessário "ocupar-se consigo", sendo um processo de intensificação e modificação da sua subjetividade:

As "artes da existência" devem ser entendidas como as práticas racionais e voluntárias pelas quais os homens não apenas determinam para si mesmos regras de conduta, como também buscam transformar-se e modificar seu ser singular, e fazer de sua vida uma obra que seja portadora de certos valores estéticos e que corresponda a certos critérios de estilo (FOUCAULT, 1989, p. 198-199).

Nessa perspectiva do cuidado consigo, não existiriam códigos exteriores e as regras de conduta deviam ser 
buscadas no próprio sujeito, na relação de si para consigo, enquanto uma ética do cuidado de si, fundada nas práticas de liberdade do sujeito.

Portanto, apesar do sujeito estar imerso em relações de poder subjetivos que tendem a objetiva-lo, ocorreriam pontos de resistência aos fluxos do poder, possibilitando escape para a expressão da subjetividade, que é pensada como um processo em movimento, sempre por se fazer em processo e produto. Nesse sentido, como processo está sempre em aberto e em movimento, dirigido para a produção de novas e diferentes formas de subjetivação ou modos de existência (modos de agir, sentir e dizer o mundo). Como produto aponta para a noção de sujeito, instante único e sempre inacabado deste processo. Por essa perspectiva, apesar de afetado pelas relações de poder, o indivíduo teria condições de resistir aos fluxos do poder que lhe afetam, criando modos de subjetivação. Logo, Foucault nos mostra a possibilidade a partir da qual o sujeito se torna sujeito da enunciação e não do enunciado.

Nesse item mostramos que para Foucault, o processo histórico pertence ao indivíduo enquanto sujeito, que é resultado de discursos produzidos que promovem a sujeição. Contudo, mesmo em sujeição, Foucault (1985) nos mostra que há originalidade e criatividade neste sujeito, já que, a partir do "cuidado de si", os sujeitos podem encontrar escape para expressar sua subjetividade, porém, sempre atrelado ao contexto social do qual faz parte, que junto das subjetividades geram novas possibilidades de sujeitos e, portanto, novas possibilidades de realidade.

A seguir, apresentaremos algumas pesquisas desenvolvidas no NESPOM-FCLAr, que aplicaram referências de Pierre Bourdieu e de Michel Foucault expostas nesse texto.

\section{Nespom: o uso do ferramental teórico de Pierre Bourdieu e Michel Foucault}

$\mathrm{O}_{\mathrm{NESPOM}}^{3}$ é um núcleo de estudos e pesquisa implantado na FCLar em 2011 e liderado pela primeira autora desse artigo. Tem como preocupação central análises do mercado e da economia, considerando que esses objetos estão imersos em relações sociais, culturais, morais, simbólicas e redes de poder. Nesse sentido, tanto os mercados, quanto a economia são considerados como construções sociais. Assim, as investigações colocam ênfase nas relações entre sociedade, poder e mercado, contribuindo em uma linha de pesquisa que se convencionou chamar de Sociologia Econômica. O núcleo, que já foi citado em artigo como referência em sociologia econômica no Brasil (NAHOUM, 2016) tem sensibilidade para a sociologia de herança simbólica, nela incluso Pierre Bourdieu. O interesse por Michel Foucault é recente no grupo, e aconteceu como desdobramento do estudo do pensamento de Bourdieu.

Em sintonia com as ideias de Bourdieu e Foucault expostas anteriormente, as pesquisas desenvolvidas no Núcleo têm demonstrado empiricamente a existência de singularidades na subjetividade nos indivíduos, apesar dos inegáveis constrangimentos sociais aos quais estão submetidos.

Nessa direção, podemos citar as pesquisas desenvolvidas por Jardim e Moura (2017) sobre o uso de aplicativo para o afeto. Nesse estudo, os autores realizam uma etnografia em dois aplicativos para relacionamento, Badoo $\odot$ e Tinder $\odot$, momento que interagem com 103 usuários do sexo masculino e realizam 15 entrevistas presenciais com alguns destes. Ademais, coletam dados em um grupo de autoajuda (Mulheres Empoderadas), que tem por objetivo ajudar mulheres a terem sucesso afetivo no uso dos aplicativos. Dentre as teorias vigentes sobre o tema, os autores concentram-se nas ideias de Illouz (2014), autora que realiza pesquisa semelhante nos Estados Unidos e conclui que os aplicativos do afeto estavam promovendo a racionalização e a intelectualização das emoções e transformando os usuários de tais aplicativos em atores racionais, como o homo economicus, em busca de afeto. Com inspiração no conceito de orquestração de habitus de Bourdieu e cuidado de si, de Foucault, os autores defendem tratar-se de outra forma de sociabilidade afetiva (não a única existente), que por sua vez estaria enraizada em elementos culturais, dotados de sentidos e para além da racionalidade do tipo homo economicus.

Apesar de em um primeiro momento os aplicativos sugerirem "o livre mercado do afeto", os autores demonstram que apesar de uma aparente abundância no mercado dos afetos, proporcionada pelos aplicativos, na prática, os aplicativos reproduzem constrangimentos sociais do "mundo real", sendo alguns deles, a valorização de determinado perfil de beleza, a valorização de determinado nível de escolaridade, domínio da língua portuguesa, estar inserido no mercado de trabalho, o seja, o/pretendente não pode estar desempregado/a. Assim, os autores negam a abundância afetiva proporcionada pelos aplicativos e também o senso comum que

${ }^{3}$ Disponível em: www.observatorionespom.com.br 
prega o "amor a primeira vista", já que as pessoas que fazem sucesso nos aplicativos são justamente aquelas que estão dentro dos padrões ditos legítimos na sociedade. Sendo assim, os aplicativos apenas reproduzem as regras da sociedade e junto com elas, as desigualdades.

Por outro lado, os autores demonstram que a racionalidade dos usuários dos aplicativos é construída socialmente, não imposta pelo aplicativo e pela lógica do mercado. A partir da análise dos depoimentos coletados, os autores demonstram que os usuários passam a (re)significar o uso do aplicativo, a partir de sua compreensão emocional sobre afeto e seus sentidos culturais, constantemente (re)trabalhados e redefinidos em diálogo com o uso somente aparentemente racional da ferramenta. Na prática, o agente faz, utilizando seu repertório cultural e cognitivo (não necessariamente consciente), julgamentos, classificações, hieraquizações e interpretação nesse espaço social. Por exemplo, o usuário que assumiu uma mulher com três filhos, porque se apaixonou por esta, para além de uma racionalidade econômica; o estrangeiro que usa o aplicativo para treinar a língua portuguesa ou a veterinária que usa o mesmo aplicativo para combinar "cruza de animais". Com diversos exemplos, os autores demostram que os usuários dos aplicativos fazem uso de códigos cognitivos individuais, da sua subjetividade construída a partir de um "cuidado de si", para interagir naquele espaço, (re)significando o aplicativo, para além da automática incorporação dessa formação discursiva.

Também não podemos deixar de citar a dissertação de mestrado de Gabriel Papa, publicada como livro (ESTEVES, 2017). Nessa pesquisa o autor, que teve como metodologia a análise do discurso foucaltiana para o estudo da imprensa, busca esclarecer a relação entre mídia e política no período pré-eleitoral e eleitoral das eleições presidenciais de 2010, para captar como se dá a representação memorial do passado na sociedade brasileira, acerca do regime militar, período que deixou marcas profundas nesta sociedade. $\mathrm{O}$ autor pesquisou a cobertura feita pelo jornal Folha de S. Paulo, pelo fato de ser um dos principais meios de comunicação a cobrir as eleições nacionais. Analisando o conteúdo discursivo, em todos os fragmentos presentes no jornal, de 01/03/2010 à 06/11/2010, como o jornal retrata os candidatos, construindo suas imagens, e relembrando seu passado opositor ao regime e como se dá a representação que a folha faz da memória da ditadura civil-militar brasileira ao cobrir as eleições de 2010. A grande mídia, enquadrada como dispositivo e como influência constitutiva de um paradoxo social, pode ser analisada através da ótica do Poder, prática social heterogeneamente presente nas sociedades humanas, aqui entendida como uma relação, algo que se exerce e não algo que se possui, algo que se dá por sua capacidade de utilizar, modificar, consumir e destruir o seu receptor. O poder é produtor de individualidades e produto delas, sendo o indivíduo seu receptor e seu reprodutor. Entramos no conceito de poder foucaultiano porque entendemos que, se assim ele se constitui, a grande mídia, em especial o sistema central de mídia brasileiro, se configura como dispositivo de poder

Refletindo acerca da relação entre mídia, memória e política, o autor aponta que, no espaço público, os meios de comunicação em massa constroem representações do passado que monumentalizam os discursos dominantes, que se disseminam pelo espaço social, levando os indivíduos a se basearem em vertentes da história, que são na realidade fragmentos da memória dos vencedores. Com essa pesquisa, o autor nos mostra o que leva a sociedade a manter-se na lógica de grupos dominantes que se mantêm assim por emergirem da crença socialmente produzida de que são legítimos (ESTEVES, 2017).

Outra possibilidade de ler o trabalho (ESTEVES, 2017) é pela perspectiva que nos sugere Bourdieu e Foucault, qual seja, apesar das relações de poder de um grupo dominante e da formação discursiva veiculada pela Folha de São Paulo, a verdade produzida por este jornal não é considerada consensual em todos os grupos sociais e por todos os agentes sociais. Isso se explicaria devido a esse escape aos discursos sugerido por Foucault, o qual permite ao sujeito realizar sua subjetivação. No mesmo sentido, o instrumenta teórico de Bourdieu nos permite notar que, apesar do poder de produzir doxa do Jornal Folha de São Paulo, devido a trajetória social (habitus) de alguns agentes, estes não seriam sensibilizados pelo Jornal podendo subverter a doxa estabelecida e reelaborar a memória social numa luta travada no espaço público pelas significações do passado e projeções da sociedade para o futuro.

Camila Benjamim Vieira (2017) realizou etnografia na feira de produtos orgânicos em Araraquara, cidade do interior do Estado de S. Paulo, em cuja feira a grande maioria dos feirantes eram assentados da reforma agrária. Essa característica é parte das trajetórias de cada produtor e por isso exerce influência em suas escolhas individuais e coletivas, o que não significa o engessamento das escolhas e estratégias e nem mesmo a homogeneidade de perfis. 
Na direção acima, a autora demonstra, por exemplo, que o conceito de lucro dos feirantes não corresponde ao conceito de lucro da teoria econômica. Com diversos exemplos antropológicos, como o uso da "cabeça" para calcular uma conta, o arredondamento dos preços dos produtos, a troca de produtos com outros feirantes, descontos especiais para clientes antigos, a autora mostra que a feira não é apenas uma estratégia de reprodução econômica, mas sobretudo espaço de reprodução social.

Como reprodução social, a autora entende o processo de socialização dos feirantes, composta por diversos elos de vínculos sociais: primeiro, a dupla atividade produtor/feira é baseada nos vínculos familiares, pela mão de obra, divisão de renda, o compartilhamento (mesmo que não legalizado) da autorização da prefeitura, a cessão da propriedade, a barraca entre parentes; segundo, para a sobrevivência na feira, os feirantes estabelecem vínculos com os demais feirantes, que apesar de conflitante em função da competição, é também harmonioso, já que a solidariedade entre os membros é variável central para a manutenção no espaço social; finalmente, a autora observou a manutenção de vínculo com fiscais da prefeitura municipal e com os próprios consumidores.

Com base em Bourdieu, a autora defende que a trajetória de vida desses sujeitos - oriundos de assentamento rural -, assim como a subjetividade dos agentes, ajudaria a explicar a forma econômica que lidam com habilidades da economia e com o próprio "fazer a feira". Da mesma forma, podemos ler seu trabalho por meio do conceito de "cuidado de si", de Foucault, já que a autora sinaliza para possível escape no processo de subjetivação dos feirantes (vínculos de solidariedade como forma de driblar as relações de poder), apesar das inúmeras coerções a que estão envolvidos.

Gabriela Porcionato (2016) estudou o campo da construção civil nos no Brasil dos anos 2000, a partir do Programa Minha Casa Minha Vida (PMCMV). Para tanto, realizou uma pesquisa etnográfica no condomínio Único Mogil, realizou entrevistas com 08 compradores de apartamentos e com o diretor da empresa Cury. A escolha da empresa Cury deu-se após estudo de ranking do setor, que a considerava umas das melhores do setor.

Uma das primeiras conclusões da autora é que o mercado da construção civil do período, foi fortemente influenciado pelo Estado, especialmente via PMCMV. Nesse contexto, a empresa Cury - experiente em habitação de alta-padrão - aderiu ao programa de casa popular. Contudo, apesar da empresa aderir ao Programa, as casas construídas por esta empresa mantiveram algumas das disposições estéticas das casas tradicionalmente construída pela empresa, uma vez que tais casas estavam localizadas em condomínio, com piscinas, área de lazer e de esporte. As casas produzidas pelas empresas estavam na faixa 2 do Programa, ou seja, com renda entre 3.500-5000 mil.

No que se refere aos consumidores, os 08 entrevistados afirmam já possuir casa própria. A aquisição do imóvel deu-se porque viram neste uma oportunidade de investimento. Assim, os entrevistados não moram no condomínio. Usando o conceito de ajustamento de habitus de Bourdieu, a autora conclui haver uma convergência de habitus entre construtora e consumidor, já que as disposições estéticas das empresas aproximaram os consumidores do produto ofertado. A pesquisa mostra que decisões econômicas são, antes de tudo, decisões sociais, pois decisões econômicas passam pelo crivo das disposições cognitivas, tanto de consumidores da casa quanto de construtores, os ofertantes do produto. Isso fica evidenciado porque mesmo que a empresa tenha aderido ao programa estatal (PMCMV), (re)significou-o de acordo com sua experiência (habitus, no sentido de Bourdieu).O mesmo fato aparece do lado dos consumidores, que (re)significou o Programa Popular.

Finalmente, o que todas as pesquisas acima têm em comum, é que em menor ou maior grau fazem uso do ferramental da sociologia de Pierre Bourdieu e de Michel Foucault, indicando o caminho da singularidade nos diferentes indivíduos estudados por estas pesquisas e da ressignificação que estes fazem diante das formações discursivas e das relações de poder, possibilitando escape para a construção da subjetividade e expressão da criatividade.

\section{CONSIDERAÇões FinaIS}

Apesar de aparentemente inconciliáveis, Foucault e Bourdieu permitem diversos diálogos, citamos dois deles: ambos estão preocupados com as relações intermediárias entre indivíduos e sociedade e os dois autores são herdeiros de uma crítica francesa de origem Durkheiminiana, a qual busca demonstrar o papel dos constrangimentos sociais, sendo que o poder assumiria o lugar de elemento coercitivo, tanto em Bourdieu quanto em Foucault. A herança Durkheiminiana é muito mais evidente em Bourdieu do que em Foucault. Contudo, apesar de negar diálogo com Durkheim, Foucault não deixa de ser um devedor deste último, quando observamos 
que o fio condutor de toda sua obra encontra-se na crítica daquilo que Durkheim chamou de "coerção social".

Com inspiração em Bourdieu e Foucault, a revisão bibliográfica indica que todo indivíduo é um agente social singular, apesar de estar submetidos às formações discursivas vigentes, que se materializam nas práticas de sujeito, que os assujeitam às diversas ordens discursivas. Assim, a subjetividade do agente seria resultante da relação estabelecida e (re)significada com o social, em diálogo com sua trajetória de vida.

$\mathrm{O}$ artigo trouxe, ainda, uma revisão bibliográfica de algumas pesquisas produzidas no NESPOM-FCLAr e que tem como fio condutor a obra de Bourdieu e de Foucault. O objetivo foi exemplificar possíveis usos dos conceitos dos autores, demonstrando empiricamente, com quatro pesquisas distintas, o papel da criatividade e o escape para a subjetividade, apesar das relações de poder e de constrangimento social existente.

Longe de esgotar o tema, o artigo poderá ser lido como um incentivo ao uso complementar da obra de dois grandes nomes da sociologia contemporânea, Pierre Bourdieu e Michel Foucault. No grupo de pesquisa NESPOM, o uso complementar dos autores é estimulado. Contudo, como o conhecimento e a aplicação da obra de Bourdieu estão mais avançados do que da obra de Foucault, o artigo pode inspirar, no grupo de pesquisa citado e em demais grupos de pesquisa, novos olhares sobre Foucault.

\section{REFERÊNCIAS}

BOURDIEU, Pierre. Langage et pouvoir symbolique. Paris: Payot, 2008.

Las estructuras sociales de la economia. Barcelona: Anagrama, 2003.

Esboço de uma teoria da prática: precedido de três estudos de etnologia kabila. Oeiras: Celta,

2002.

O poder simbólico. Rio de Janeiro, RJ: Bertrand Brasil, 2000.

A dominação masculina. Rio de Janeiro, RJ: Bertrand Brasil, 1999.

Razões Práticas. Sobre a teoria da ação. Campinas, SP: Papirus, 1996.

Questions de sociologie. Paris: Minuit, 1980.

. Desencantamento do mundo - Estruturas econômicas e estruturas temporais. São Paulo, SP: Elos: Perspectiva, 1979.

ESTEVES, Gabriel Papa R. O Paradoxo da Realidade Social: Mídia, Memória e Ditadura no Brasil. Curitiba, PR: Appris, 2017.

FOUCAULT, Michel. A criação do biopoder, In: . Defesa da sociedade. São Paulo, SP: Martins Fontes, 1999.

1997.

Resumo dos Cursos do Collège de France 1970-1982, Rio de Janeiro, RJ: Jorge Zahar Editor Ltda, A Ordem do Discurso. $3^{a}$ ed. São Paulo, SP: Edições Loyola, 1996.

. O Sujeito e Poder. In: DREYFUS, H.; RABINOW, P. Michel Foucault: uma trajetória filosófica.

Para além do estruturalismo e da hermenêutica. Rio de Janeiro, RJ: Forense Universitária, 1995, p. 253-291.

Dits e écrits IV. Paris: Gallimard, 1994. 
. História da sexualidade I: A vontade de saber. Rio de Janeiro, RJ: Edições Graal, 1988.

Vigiar e Punir: nascimento da prisão. 4a ed. Petrópolis, RJ: Vozes, 1986.

História da sexualidade III: O cuidado de si. Rio de Janeiro, RJ: Edições Graal, 1985.

198-199.

Ditos e Escritos V - O Uso dos Prazeres e as Técnicas de Si. Rio de Janeiro, RJ: Graal, 1983, p. Microfísica do Poder. Rio de Janeiro, RJ: Graal, 1979.

GIDDENS, A.; TURNER, J. (Orgs.). Teoria Social Hoje. São Paulo, SP: Ed. UNESP, 1999.

MARX, Karl. O Capital - Crítica da Economia Política. Livro I. São Paulo, SP: Civilização Brasileira. 2008.

ILLOUZ, Eva. Hard-Core Romance: "Fifty Shades of Grey," Best-Sellers, and Society. Chicago: University of Chicago Press, 2014.

JARDIM, M. A. C.; CAMPOS, Ricardo Sapia. A Construção social dos mercados e a crítica da Ciência Econômica. REDD - Revista de Espaço de Diálogo e Desconexão, Araraquara/SP, v. 4, n. 2, Jan/Jul. 2012.

MOURA, P. J. C. A construção social do mercado de dispositivos de redes sociais: a contribuição da sociologia econômica para os aplicativos de afeto. Revista Tomo, v. 30, p. 151-197, 2017.

NAHOUM, André Vereta. A Sociologia econômica no Brasil: Balanço de um campo jovem. São Paulo, SP: Ateliê Editorial, 2017.

PORCIONATO, Gabriela Lanza. Programa Minha Casa Minha Vida: a construção social de um mercado. Dissertação (Mestrado em Ciências Sociais). Programa de Pós-graduação em Ciências Sociais da Universidade Estadual Paulista, Faculdade de Ciências e Letras de Araraquara. Araraquara/SP, 2016.

VIEIRA, Benjamim Camila. O fazer a feira: a feira noturna da agricultura familiar de Araraquara-SP como espaço de reprodução social e econômica. Dissertação (Mestrado em Ciências Sociais). Programa de Pós-graduação em Ciências Sociais da Universidade Estadual Paulista, Faculdade de Ciências e Letras de Araraquara. Araraquara/SP, 2017. 